\title{
A Biotin-Regulated Locus, bioS, in a Possible Survival Operon of Rhizobium meliloti
}

\author{
Wolfgang R. Streit and Donald A. Phillips \\ Department of Agronomy and Range Science, University of California, Davis 95616, U.S.A. \\ Received 25 February 1997. Accepted 18 June 1997.
}

\begin{abstract}
A novel biotin-inducible DNA locus, bioS, was found in Rhizobium meliloti 1021 by mutation with a transposable promoter probe. The promoterless nptII reporter responded to $40 \mathrm{nM}$ biotin with a sixfold increase in NPTII protein. Stationary-phase mutant cells accumulated $50 \%$ more ${ }^{14} \mathrm{C}$-biotin than corresponding wild-type cells. The prototrophic mutant competed equally with the wild type in biotin-free medium but poorly when $40 \mathrm{nM}$ biotin was present. The 588-bp bioS is located among three genes showing homology to survival operons of other bacteria, and it may be part of a system that $R$. meliloti uses to respond to plant biotin signals.
\end{abstract}

Additional keywords: Medicago sativa, rhizosphere ecology.

Low numbers of Rhizobium meliloti cells $\left(<10^{4}\right.$ CFU per $\mathrm{g}$ of soil) occur in soils where alfalfa (Medicago sativa L.) and other Medicago spp. have grown (Bottomley and Jenkins 1983; Brockwell et al. 1991). Little is known about how those small populations succeed in colonizing their normal host plants, but signal molecules released by the root may play an important role (Phillips and Streit 1996). Biotin is one molecule that is exuded by alfalfa roots (Rovira and Harris 1961) and promotes colonization by $R$. meliloti (Streit et al. 1996). It is not known if $R$. meliloti has a unique mechanism for responding to plant-derived biotin.

Biotin is a vitamin best known for its function as a cofactor binding $\mathrm{CO}_{2}$ in enzymes, such as pyruvate carboxylase in $R h i$ zobium etli (Dunn et al. 1996). Classical studies established that exogenous biotin generally is not essential but often promotes growth of Rhizobium in pure culture (West and Wilson 1939). Presumably that response is linked to the $\mathrm{CO}_{2}$ requirement for growth of Rhizobium and Bradyrhizobium (Lowe and Evans 1962). Biotin affects transcription of Escherichia coli genes required for biotin synthesis (Cronan 1989), but there are no reports of other prokaryotic genes being regulated by this molecule. Rhizosphere bacteria responding to plantderived biotin with increased growth may have a competitive advantage over non-responsive cells and thereby occupy favorable niches on root surfaces. Thus, one could postulate that

Corresponding author: D. A. Phillips; Telephone: (916) 752-1891; Fax: (916) 752-4361; E-mail: daphillips@ucdavis.edu

Nucleotide and/or amino acid sequence data have been submitted to GenBank as accession number U81296. external biotin may induce a biotin-uptake system or other genes involved in converting $R$. meliloti cells from a resting or slow-growing state in soil to a fast-growing rhizosphere bacterium. To explore whether external biotin regulates any unique $R$. meliloti genes, a mutant bank was created in $R$. meliloti 1021 (Rm1021) (Meade et al. 1982) with transposable promoter probe Tn5-B30(nptII) (Simon et al. 1989). We offer here an initial report on a novel biotin-inducible DNA locus found with this approach.

Of 3,000 mutants carrying the promoterless nptII reporter, one was identified, Rm1021-B5, that showed biotin-enhanced growth on agar plates containing kanamycin $(200 \mu \mathrm{g} / \mathrm{ml})$. Growth tests and NPTII protein measurements confirmed that expression of the nptII marker in Rm1021-B5 was regulated by biotin and correlated with the increased growth on kanamycin (Fig. 1). Doubling time in liquid medium containing kanamycin decreased markedly in the presence of $0.4 \mathrm{nM}$ biotin and declined more than 13-fold with $40 \mathrm{nM}$ biotin (Fig. 1A). NPTII protein increased significantly with $0.4 \mathrm{nM}$ biotin in the medium, and a sixfold increase in NPTII protein was observed with $40 \mathrm{nM}$ biotin (Fig. 1B). Cells for these experiments were grown to stationary phase in GTS medium (Kiss et al. 1979) without biotin, centrifuged, resuspended in fresh GTS, supplemented with various concentrations of biotin, and incubated $5 \mathrm{~h}$ at $28^{\circ} \mathrm{C}$ to induce the $n p t I I$ gene. Bacteria were harvested by centrifugation and lysed, and NPTII protein was measured with an NPTII enzyme-linked immunosorbent assay kit (5Prime-3Prime, Boulder, CO). Because Tn5-B30 is a transcriptional fusion, these data indicate the mutated locus is biotin-induced. It is possible, however, that the biotin regulation occurs indirectly through some other biotin-dependent event.

Growth tests with biotin-depleted cells inoculated from stationary phase into GTS medium containing $4 \mathrm{nM}$ to $4 \mu \mathrm{M}$ biotin showed that wild-type cells began growing 6 to $8 \mathrm{~h}$ sooner than the mutant (data not shown). This phenotype is associated with the site of insertion and not simply with transcription of nptII because other Tn5-B30 mutants of Rm1021 showed no extension of the normal lag period (Streit et al. 1996). There were no differences in viability between Rm1021 and Rm1021-B5 cells after 3 and 6 days in stationary phase following growth with either 0 or $40 \mathrm{nM}$ biotin. Thus, taken as a whole, these findings suggest the mutated locus affects resumption of growth in resting cells but has no effect on survival per se in stationary phase under the conditions tested. 
In dual-culture tests, wild-type cells outcompeted the mutant in GTS medium containing $40 \mathrm{nM}$ biotin (Fig. 2). In one experiment the mutant increased from $6.0 \times 10^{5}$ to $1.3 \times 10^{8}$ $\mathrm{CFU} / \mathrm{ml}$ during $48 \mathrm{~h}$, but wild-type cells in co-culture increased from $6.5 \times 10^{5}$ to $7.55 \times 10^{8} \mathrm{CFU} / \mathrm{ml}$ over the same period. The resulting decline in mutant/wild type ratio was highly significant $(P \leq 0.05)$ and served as a phenotypic test for complementing the mutation. No significant change in the mutant/wild type ratio was observed either in the absence of biotin (Fig. 2) or when $40 \mu \mathrm{M}$ biotin was present (data not shown).

The mutation in Rm1021-B5 greatly enhanced accumulation of ${ }^{14} \mathrm{C}$-biotin in biotin-depleted stationary-phase cells (Fig. 3). These experiments were conducted with cells grown 4 days in GTS medium containing no added biotin. On day 3, avidin $(1 \mathrm{mU} / \mathrm{ml})$ was added to remove all traces of biotin, and $24 \mathrm{~h}$ later bacteria were pelleted, washed twice with avidin-free GTS, adjusted to $\mathrm{OD}_{600}=0.5$, and placed in GTS containing $60 \mathrm{nM}$ D-carbonyl- ${ }^{14} \mathrm{C}$-biotin $(8.12 \mathrm{MBq}$ of biotin per mg; Amersham, Buckinghamshire, UK). The ${ }^{14} \mathrm{C}$ in bacteria was measured in 1-ml aliquots of cells harvested by filtration on nylon membranes $(0.2 \mu \mathrm{m}$ pore size, $22 \mathrm{~nm}$ diameter; MSI, Westboro, MA), washed three times with GTS, dried, and quantified in Scintiverse RD solution (Fisher, Pittsburgh, PA) with a scintillation counter (LS8000, Beckman, Fullerton, $\mathrm{CA})$. Values were corrected for background ${ }^{14} \mathrm{C}$, and disinte-

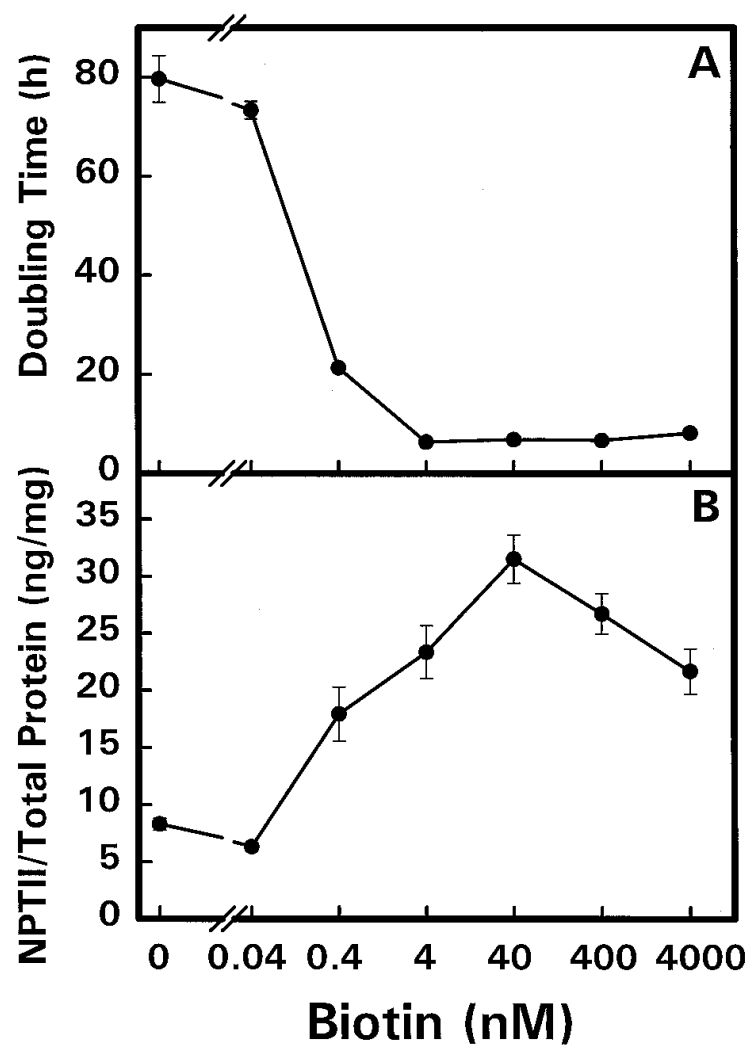

Fig 1. Biotin effects on expression of the bioS::Tn5-nptII locus in Rm1021-B5. A, Biotin-dependent growth in GTS medium containing $220 \mu \mathrm{g}$ of kanamycin per ml. B, Biotin-dependent production of NPTII protein from the promoterless $n$ ptII. All values are means $( \pm$ standard error) from three replicate cultures. grations were converted to $\mathrm{ng}{ }^{14} \mathrm{C}$-biotin by using an external standard. After $60 \mathrm{~min}, 30$ to $50 \%$ more ${ }^{14} \mathrm{C}$ was measured reproducibly in the mutant than in $\mathrm{Rm} 1021(P \leq 0.05)$. A subsequent 40 -min treatment in excess ${ }^{12} \mathrm{C}$-biotin decreased cellular ${ }^{14} \mathrm{C}$ content no more than 15 to $20 \%$ (data not shown). Thus, most ${ }^{14} \mathrm{C}$ measured was in bacterial cells and was not bound as exchangeable biotin on the cell surface. No differ-

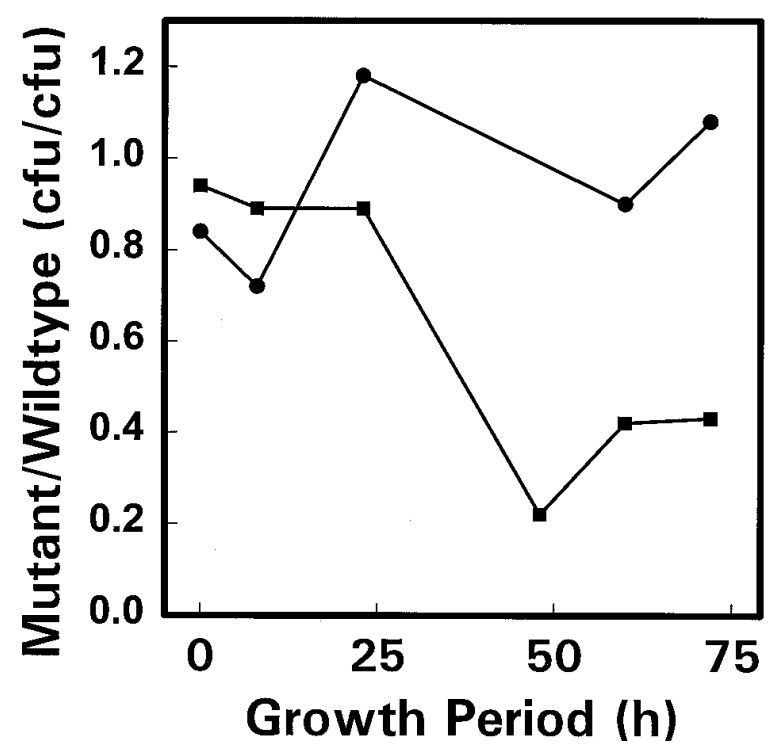

Fig 2. Biotin effects on competitive growth of Rm1021 and Rm1021B5. Similar ratios of stationary-phase cells (mutant/wild type) were inoculated into GTS medium without supplemental biotin (--) or with 40 nM biotin (--). Symbols denoting mean values of viable cells from three replicate cultures obscure the smaller standard error bars.

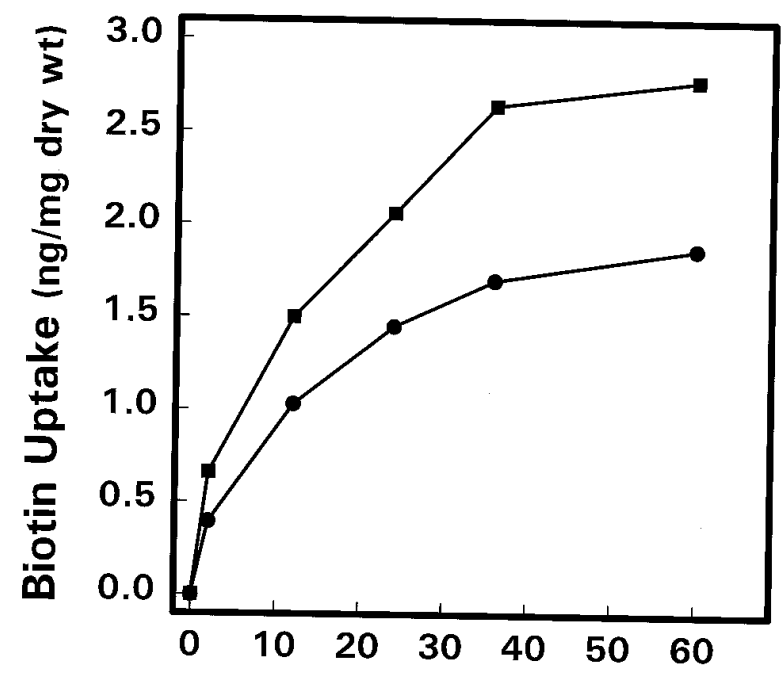

\section{Uptake Period (min)}

Fig 3. Biotin uptake by Rm1021 (-0-) and Rm1021-B5 (-口-) cells. Cells grown under biotin-free conditions to stationary phase were supplied with ${ }^{14} \mathrm{C}$-biotin at time 0 . Mean value symbols from three replicate cultures obscure the smaller standard error bars. 
ence in exchange of ${ }^{12} \mathrm{C}$ - for ${ }^{14} \mathrm{C}$-biotin was observed between Rm1021 and mutant strain Rm1021-B5.

Cosmid clone pCosRmB5, which carries Rm1021 DNA in pSUP205 (Simon et al. 1983), was isolated for complementation and structural studies of the mutated DNA locus. To locate this cosmid clone in wild-type DNA, an appropriate digoxigenin-labeled probe (Boehringer Mannheim, Mannheim, Germany) was made from Rm1021-B5 DNA. After EcoRI restriction and religation of the mutant DNA, Tn5-specific primer Tn5out (Streit et al. 1996) was used in a 35-cycle polymerase chain reaction to amplify a $1.5-\mathrm{kbp}$ DNA fragment. A single band was detected on a $1.2 \%$ agarose gel and isolated for use as a probe. This DNA probe formed strong hybridization signals with a $1.5-\mathrm{kb}$ fragment of Rm1021 DNA and with a 7.8-kb piece of Rm1021-B5 DNA corresponding to the mutated DNA locus. A partial restriction map of pCosRmB5 (Fig. 4A) was generated with DNA modifying enzymes (Promega, Madison, WI). DNA fragments identified by that map were subcloned in pBSK+ (Stratagene, La Jolla, CA), and both strands were sequenced automatically (ABI377, Applied Biosystems Perkin-Elmer, Foster City, CA) to define open reading frames (ORFs) surrounding the Tn5 insertion (Fig. 4A). Putative transcriptional start sites were identified by the PC/GENE DNA analysis software (IntelliGenetics, LO-
CATION). Sequence data from a 4,153-bp fragment containing ORFs I, II, III and IV were submitted to the GenBank (NCBI) data base as accession number U81296.

The transposon-mutated ORF III (Fig. 4A), which we term bioS and identify as a 588-bp sequence, contained a putative ribosome binding site and a probable translational start site (data available as accession number U81296). The deduced amino acid sequence for ORF III contains 195 residues. Searches of NCBI data banks showed no significant homology of bioS to any bacterial gene for either amino acid or nucleotide sequences in six possible reading frames. However, DNA adjacent to bioS contained three other ORFs with notable homologies to previously reported bacterial genes (Table 1).

Conservative comparisons for identical amino acids across the entire protein, as well as the more specific local alignment tests (Altschul et al. 1990), offered convincing evidence that Rm1021 ORFs I (771 bp), II (615 bp), and IV (1,539 bp) correspond to known bacterial genes. Homologies of the ORFs, which are based on identification of a putative start site in each ORF, suggest that in $R$. meliloti the surE homologue (ORF I) codes for a 256-amino-acid protein, the $\mathrm{pcm}$ homologue (ORF II) codes for a 204-amino-acid methyltransferase, and the $\operatorname{lppB} / \mathrm{nlpD}$ homologue (ORF IV) codes for a 512amino-acid protein. Organization of the $s u r E$, pcm, and $l p p B /$

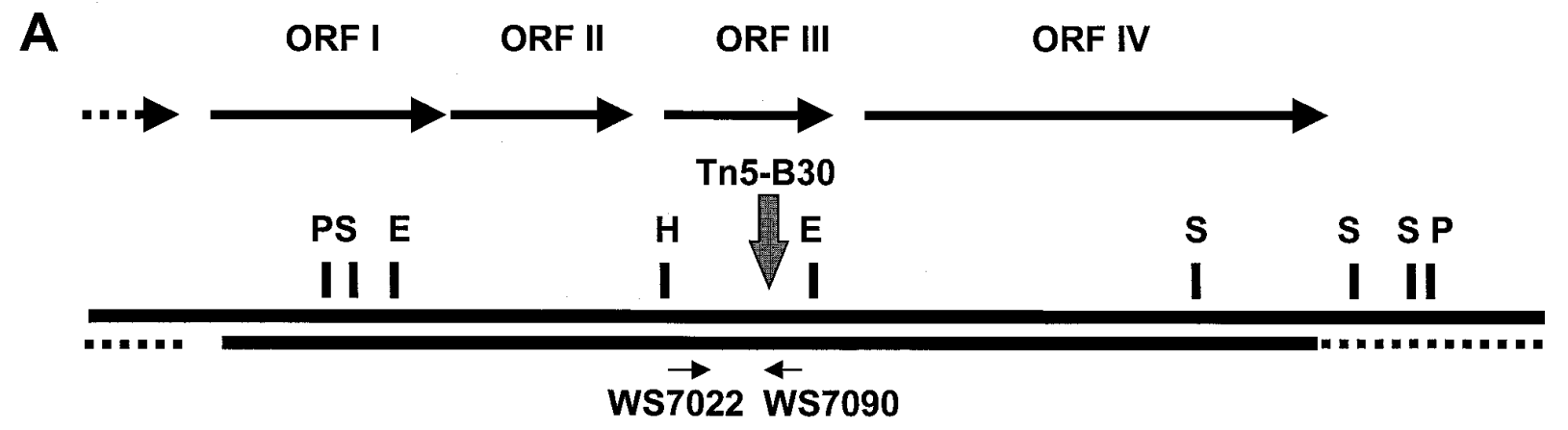

B

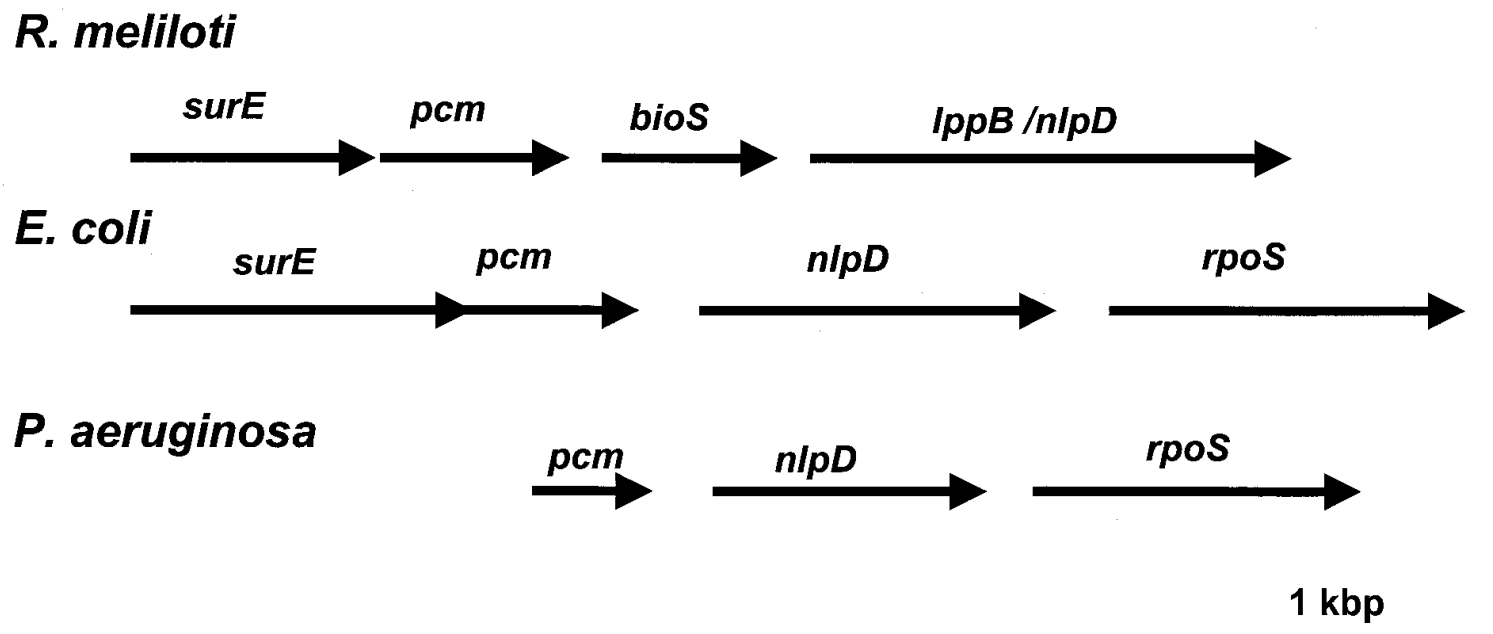

Fig 4. Location of a biotin-regulated DNA locus in Rhizobium meliloti 1021. A, Four open reading frames (horizontal arrows) and the Tn5 insertion site in Rm1021-B5 (vertical arrow) were defined by nucleotide sequencing. A solid line under the restriction map (S: SalI; H: HindIII; E: EcoRI; P: PstI) corresponds to GenBank accession number U81296; dotted lines show adjacent regions examined for homologies. WS7022 and WS7090 are primer sites within bioS. B, Genes identified near bioS by deduced amino acid sequences. 
$n l p D$ homologues in $R$. meliloti follows the same patterns described for the survival operons of E. coli (Li et al. 1994) and P. aeruginosa (Fujita et al. 1994) (Fig. 4B). In a bacterium containing 3,000 genes, the probability that three genes would occur in such an identical order as a result of random events is exceedingly small $\left(P \leq 3.7 \times 10^{-11}\right)$. Local alignment analyses of ORFs I and IV also showed significant identities to the Haemophilus influenzae genes $\operatorname{surE}\left(P \leq 7.5 \times 10^{-49}\right)$ and $\operatorname{lppB}$ $\left(P \leq 2.9 \times 10^{-14}\right)$, which are not organized in a single operon (Fleischmann et al. 1995). Taken together, these results suggest that the novel biotin-regulated DNA locus, bioS, in $R$. meliloti is located in a survival operon. Data from this study showed no strong effect of bioS on currently recognized stationary-phase functions. Indeed, because disruption of the $E$. coli nlpD gene impairs survival (Ichikawa et al. 1994), the observation here that Rm1021-B5 showed normal viability in stationary phase suggests that bioS has no effect on transcription of the $n l p D$ homologue in $R$. meliloti. At the same time, however, the ${ }^{14} \mathrm{C}$-biotin uptake tests showed a major effect of the bioS in stationary-phase cells (Fig. 3) but no effect on logphase cells (data not shown). These results suggest that bioS is related in some way to stationary-phase functions and that biotin plays a role in that process.

In $E$. coli and $P$. aeruginosa the $l p p B / n l p D$ gene is followed immediately by rpoS (Fujita, et al. 1994; Ichikawa et al. 1994; Ivanova et al. 1992; Mulvey and Loewen 1989). Sequencing 2,274 bp downstream of $R$. meliloti lppB/nlpD showed no significant homology to $\operatorname{rpoS}$ sequences available in the data bases.

Hybridization studies with genomic DNA suggest that Rm1021 has a second locus closely related to bioS (Fig. 5). In those experiments with EcoRI-digested DNA of Rm1021 and Rm1021-B5, a bioS-specific DNA probe, which was generated with polymerase chain reaction primers WS7022 (5'CCG TGC AAG CTT CCC GCT TTA GGT3') and WS7090 (5'CTG TTC TGA TCC TTC CGG GGC GAA G3') (Fig. $4 \mathrm{~A}$ ), detected one $1.5 \mathrm{~kb}$ fragment in Rm1021 and a corresponding 7.8-kb fragment containing Tn5-B30 in Rm1021-B5. In addition, under stringent hybridization conditions $\left(68^{\circ} \mathrm{C}\right)$, an 11-kb DNA fragment was detected in both strains (Fig. 5).

Mutant Rm1021-B5 was complemented successfully with pCosRmB5, which contained the wild-type bioS locus from Rm1021. Transconjugants were recovered on GTS medium with appropriate antibiotics (tetracycline, $2 \mu \mathrm{g} / \mathrm{ml}$; chloramphenicol, $50 \mu \mathrm{g} / \mathrm{ml}$ ) and were grown twice to stationary phase in biotin-free GTS medium. To test if the impaired competition phenotype of the mutant (Fig. 2) was corrected, trans- conjugant cells were diluted and inoculated together with an equal number of Rm1021 cells into GTS medium containing $40 \mathrm{nM}$ biotin. Under these conditions the transconjugant/wild type ratios remained near 1.0 for $72 \mathrm{~h}$ after inoculation. In one test with Rm1021-WS13 (Rm1021-B5pCosRmB5) the trans-

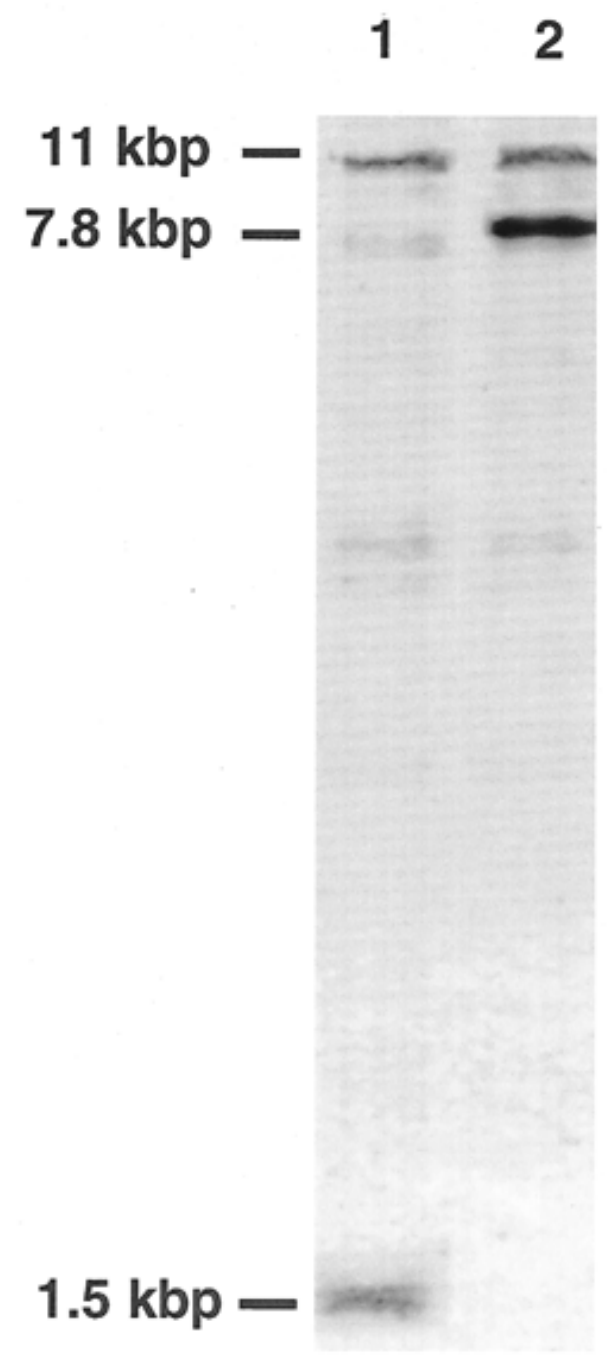

Fig 5. Southern blot analysis of genomic Rhizobium meliloti DNA after complete EcoRI digestion. Gel blots were probed with a bioS-derived fragment labeled with digoxigenin. The 7.8-kb signal reflects bioS $(1.5$ kb) plus $6.3 \mathrm{~kb}$ from Tn5-B30. Lane 1: Rm1021; lane 2: Rm1021-B5.

Table 1. Comparisons of deduced amino acids in known genes with Rm1021 open reading frames (ORFs)

\begin{tabular}{|c|c|c|c|c|c|c|}
\hline \multirow[b]{3}{*}{ Species } & \multirow[b]{3}{*}{ Gene } & \multirow[b]{3}{*}{$\operatorname{Rm}_{1021}$ ORF $^{\mathrm{a}}$} & \multicolumn{4}{|c|}{ Method of analysis } \\
\hline & & & \multicolumn{2}{|c|}{ Complete protein ${ }^{b}$} & \multicolumn{2}{|c|}{ Local alignment $^{c}$} \\
\hline & & & Identity (\%) & Similarity (\%) & Identity $(\%)$ & $P$ \\
\hline \multirow[t]{3}{*}{ Escherichia coli } & surE & I & 38 & 54 & 40 & $1.3 \times 10^{-57}$ \\
\hline & pcm & II & 29 & 51 & 29 & $9.2 \times 10^{-30}$ \\
\hline & nlpD & IV & 18 & 30 & 38 & $1.2 \times 10^{-18}$ \\
\hline \multirow[t]{2}{*}{ Pseudomonas aeruginosa } & pcm & II & 36 & 56 & 36 & $3.0 \times 10^{-7}$ \\
\hline & $n l p D$ & IV & 26 & 40 & 36 & $2.2 \times 10^{-25}$ \\
\hline
\end{tabular}

${ }^{a}$ ORFs from Figure 4A.

${ }^{\mathrm{b}}$ Percentage of identical or functionally similar amino acids in the entire protein.

${ }^{c}$ Percentage of identical amino acids found by local alignment of oligopeptide fragments (Altschul et al. 1990) and the probability of nonrandomness. 
conjugant/wild type ratio was 1.2 at the time of inoculation and 1.1 after $72 \mathrm{~h}$. In the same experiment original mutant $\mathrm{Rm} 1021-\mathrm{B} 5$ was inoculated together with $\mathrm{Rm} 1021$ at a ratio of 1.1 , and a mutant/wild type ratio of 0.4 was measured after $72 \mathrm{~h}$. Polymerase chain reaction analyses of Rm1021-WS13 with primers WS7022 and WS7090 (Fig. 4A) to amplify the wild-type bioS gene confirmed the presence of the predicted 509-bp DNA fragment in the transconjugant strain and its absence in mutant Rm1021-B5.

Microbiologically controlled tests for root colonization of alfalfa plants (Streit et al. 1996) detected no phenotypic difference between Rm1021 and Rm1021-B5 (data not shown). Experiments comparing growth and colonization by Rm1021 and Rm1021-B5 cells supplied separately and together at low cell numbers ( $<200$ cells per plant) repeatedly showed no differences between the two strains after 2 and 6 days on the root. In all cases, mutant and wild-type cells were equally competitive when they were inoculated from cultures grown to early log phase or late stationary phase under various biotin concentrations. Such results may reflect the presence of a second, structurally related DNA locus (Fig. 5).

The most striking result from this work is the demonstration that $R$. meliloti 1021 contains a novel biotin-inducible DNA locus, bioS, that responds to external biotin. Cells mutated in this locus accumulated 40 to $50 \%$ more biotin than wild-type cells after $60 \mathrm{~min}$ in $60 \mathrm{nM}$ biotin (Fig. 3). One explanation for this result would be that biotin uptake is poorly regulated in the mutant, but a change in biotin turnover or metabolism could produce the same result. Exactly how bioS might be involved in responding to plant-derived biotin in the rhizosphere is unclear at this time. Cells mutated in bioS were equally competitive with wild-type cells in the rhizosphere even though they were less competitive under low biotin conditions in laboratory culture (Fig. 2). The intriguing presence of a second DNA fragment, structurally related to bioS (Fig. 5), suggests that a strain mutated in both loci may help define the role of bioS. Discussions of biotin as a regulatory molecule in bacteria have centered on how this molecule controls biotin synthesis and on its use as a carboxylase cofactor (Cronan 1989). Within that context, bioS is the first biotin-regulated DNA locus identified in prokaryotes outside those genes involved in biotin synthesis, and defining its function may help clarify roles for biotin signals in rhizosphere ecology.

\section{ACKNOWLEDGMENTS}

This work was supported by US National Science Foundation grant IBN-92-18567. W. R. Streit was supported in part by a Feodor von Lynen Stipend from the Alexander von Humboldt Foundation.

\section{LITERATURE CITED}

Altschul, S. F., Gish, W., Miller, W., Myers, E. W., and Lipman, D. J. 1990. Basic local alignment search tool. J. Mol. Biol. 215:403-410.

Bottomley, P. J., and Jenkins, M. B. 1983. Some characteristics of Rhizobium meliloti isolates from alfalfa fields in Oregon. Soil Sci. Soc. Am. J. 47:1153-1157.
Brockwell, J., Pilka, A., and Holliday, R. A. 1991. Soil pH is a major determinant of the numbers of naturally occurring Rhizobium meliloti in non-cultivated soils in central New South Wales. Aust. J. Exp. Agric. 31:211-219.

Cronan, J. E. 1989. The E. coli bio operon: Transcriptional repression by an essential protein modification enzyme. Cell 58:427-429.

Dunn, M. F., Encarnación, S., Araíza, G., Vargas, M. C., Dávalos, A., Peralta, H., Mora, Y., and Mora, J. 1996. Pyruvate carboxylase from Rhizobium etli: Mutant characterization, nucleotide sequence, and physiological role. J. Bacteriol. 178:5960-5970.

Fleischmann, R. D., Adams, M. D., White, O., Clayton, R. A., Kirkness, E. F., Kerlavage, A. R., Bult, C. J., Tomb, J. F., Dougherty, B. A., Merrick, J. M., McKenney, K., Sutton, G., Fitzhugh, W., Fields, C., Gocayne, J. D., Scott, J., Shirley, R., Liu, L. I., Glodek, A., Kelley, J. M., Weidman, J. F., Phillips, C. A., Spriggs, T., Hedblom, E., Cotton, M. D., Utterback, T. R., Hanna, M. C., Nguyen, D. T., Saudek, D. M., Brandon, R. C., Fine, L. D., Fritchman, J. L., Fuhrmann, J. L., Geoghagen, N. S. M., Gnehm, C. L., McDonald, L. A., Small, K. V., Fraser, C. M., Smith, H. O., and Venter, J. C. 1995. Whole-genome random sequencing and assembly of Haemophilus influenzae Rd. Science 269:496-512.

Fujita, M., Tanaka, K., Takahashi, H., and Amemura, A. 1994. Transcription of the principal sigma-factor genes, rpoD and rpoS, in Pseudomonas aeruginosa is controlled according to the growth phase. Mol. Microbiol. 13:1071-1077.

Ichikawa, J. K., Li, C., Fu, J., and Clarke, S. 1994. A gene at 59 minutes on the Escherichia coli chromosome encodes a lipoprotein with unusual amino acid repeat sequences. J. Bacteriol. 176:1630-1638.

Ivanova, A., Renshaw, M., Guntaka, R. V., and Eisenstark, A. 1992. DNA base sequence variability in katF (putative sigma-factor) gene of Escherichia coli. Nucleic Acids Res. 20:5479-5480.

Kiss, G. B., Vincze, E., Kalman, Z., Forrai, T., and Kondorosi, A. 1979. Genetic and biochemical analysis of mutants affected in nitrate reduction in Rhizobium meliloti. J. Gen. Microbiol. 113:105-118.

Li, C., Ichikawa, J. K., Ravetto, J. J., Kuo, H. C., Fu, J. C., and Clarke, S. 1994. A new gene involved in stationary-phase survival located at 59 minutes on the Escherichia coli chromosome. J. Bacteriol. 176: 6015-6022.

Lowe, R. H., and Evans, H. J. 1962. Carbon dioxide requirement for growth of legume nodule bacteria. Soil Sci. 94:351-356.

Meade, H. M., Long, S. R., Ruvkun, G. B., Brown, S. E., and Ausubel, F. M. 1982. Physical and genetic characterization of symbiotic and auxotrophic mutants of Rhizobium meliloti induced by transposon Tn5 mutagenesis. J. Bacteriol. 149:114-122.

Mulvey, M. R., and Loewen, P. C. 1989. Nucleotide sequence of katF of Escherichia coli suggests katF protein is a novel sigma-transcription factor. Nucleic Acids Res. 17:9979-9991.

Phillips, D. A., and Streit, W. R. 1996. Legume signals to rhizobial symbionts: A new approach for defining rhizosphere colonization, Pages 236-271 in: Plant-Microbe Interactions. Vol. 1. G. Stacey and N. T. Keen, eds. Chapman \& Hall, New York.

Rovira, A. D., and Harris, J. R. 1961. Plant root excretions in relation to the rhizosphere effect V. The exudation of B-group vitamins. Plant Soil 14:199-214.

Simon, R., Priefer, U., and Pühler, A. 1983. A broad host range mobilization system for in vivo genetic engineering: Transposon mutagenesis in Gram-negative bacteria. Bio/Technology 1:784-791.

Simon, R., Quandt, J., and Klipp, W. 1989. New derivatives of transposon Tn5 suitable for mobilization of replicons, generation of operon fusions and induction of genes in Gram-negative bacteria. Gene 80: 161-169.

Streit, W. R., Joseph, C. M., and Phillips, D. A. 1996. Biotin and other water-soluble vitamins are key growth factors for alfalfa root colonization by Rhizobium meliloti 1021. Mol. Plant-Microbe Interact. 9: 330-338.

West, P. M., and Wilson, P. W. 1939. Growth factor requirements of the root nodule bacteria. J. Bacteriol. 37:161-185. 